\title{
Functional and Cognitive Status in Clostridium difficile Infection in the Hospitalized Elderly: a Retrospective Study of Two Sites
}

\begin{abstract}
Maria-Jose Fernandez-Cotarelo, MD, $P h D^{1,2}$, Stephanie E. Nagy-Agren, MD³, Mark E. Smolkin, MS4, Leticia Jimenez-Diez-Canseco, MD ${ }^{1}$, Maria-Teresa Perez-Pomata, MD ${ }^{5}$, Brian V. Shenal, PhD ${ }^{6}$, and Cirle A. Warren, $\mathrm{MD}^{7}$

'Department of Internal Medicine, Hospital Universitario de Mostoles, Madrid, Spain; ${ }^{2}$ Faculty of Health Sciences, Universidad Rey Juan Carlos, Madrid, Spain; ${ }^{3}$ Department of Infectious Disease, Salem Veterans Affairs Medical Center, Virginia Tech Carilion School of Medicine and Research Institute, Roanoke, VA, USA; ${ }^{4}$ University of Virginia School of Medicine, Charlottesville, VA, USA; ${ }^{5}$ Department of Microbiology, Hospital Universitario de Mostoles, Madrid, Spain; ${ }^{6}$ Center for Neurocognitive Services, Salem Veterans Affairs Medical Center, Roanoke, VA, USA; ${ }^{7}$ Division of Infectious Disease and International Health, University of Virginia, Charlottesville, VA, USA.
\end{abstract}

KEY WORDS: Clostridium difficile infection; elderly; functional debility; cognitive impairment; gut microbiota.

J Gen Intern Med 34(8): 1392-3

DOI: $10.1007 / \mathrm{s} 11606-019-04935-6$

(๑) Society of General Internal Medicine 2019

\section{INTRODUCTION}

Advanced age is a risk factor for Clostridium difficile infection (CDI), and older patients have more severe CDI and worse outcome. ${ }^{1-3} \mathrm{We}$ investigated whether CDI in the elderly is associated with functional and cognitive decline, and mortality.

\section{METHODS}

This is an IRB-approved two-center case-control study, with retrospective review of the EMR in Salem Veterans Affairs Medical Center (VAMC) in Virginia, and Hospital Universitario de Mostoles (HUM) in Madrid (Spain). Cases were patients aged $60+$ years old diagnosed with CDI during 2013 and 2014 using Cepheid GeneXpert at VAMC, and $C$. Diff Quick Check Complete (TechLab, Blacksburg, VA, USA) (2013) and Portrait Toxigenic C. difficile Assay (Great Basin Corp, UT, USA) (2014) at HUM. Controls were randomly selected from patients without a diagnosis of CDI, matched to cases by age, sex, and Charlson Comorbidity Index (CCI). Other variables recorded were pre-hospitalization dwelling, cognitive conditions, functional status, development of delirium, length of stay, readmissions, and mortality, and for cases, case-definition and severity. Cases and controls were tracked up to 180 days after diagnosis and discharge, respectively.

Maria-Jose Fernandez-Cotarelo and Stephanie E. Nagy-Agren contributed equally to this work.

Published online March 19, 2019

\section{RESULTS}

One hundred six patients were diagnosed with CDI, mean age 76.3. The mean CCI was 5 and 2.3 and hospital onset CDI was $70.4 \%$ and $67.4 \%$ in VAMC and HUM, respectively. There was higher baseline functional debility in cases compared to controls $(84 \%$ vs. $69 \%, p=0.014)$. Cases were more likely to be admitted from nursing home (NH) or long-term care facility (LTCF) $(22 \%$ vs. $8 \%$ of controls, $p=0.006$ ). Severity of CDI was significantly associated with age $80+$ years and admission for CDI.

Six cases died during admission at each site. CDI cases with dementia had higher in-hospital mortality (24\%) compared to those without dementia $(8 \%, p=0.044)$. Mortality was higher for cases during hospitalization and at 90 and 180 days (Table 1). CDI cases experienced delirium during hospitalization two times more than controls. Discharge to NH/LTCF, functional decline, or death during admission was significantly worse for cases. Readmission (after correction for mortality) was not significantly different. Within the case group (Table 2), dementia was also significantly associated with functional decline or death, as was delirium. Analysis of mortality at later timepoints revealed dementia to be significantly associated with death at 90 and 180 days (Table 2).

\section{DISCUSSION}

The association of CDI with cognitive impairment, functional decline, and delayed mortality in the elderly shown by this study indicates that CDI may have consequences beyond acute intestinal infection.

Debility and cognitive impairment were previously reported to be associated with prolonged symptoms and severity of CDI. ${ }^{3,4}$ In our study, functional decline or death during hospitalization was more common in cases than matched controls suggesting that given the same degree of comorbidities, elderly patients who develop CDI are sicker and at risk of poor outcomes. We found that those with diagnosis of either dementia or delirium among cases were particularly more likely 
Table 1 Outcomes of Cases and Controls

\begin{tabular}{|c|c|c|c|}
\hline & $\begin{array}{l}\text { Cases } n / \text { total } \\
(\%)\end{array}$ & $\begin{array}{l}\text { Controls } n / \text { total } \\
(\%)\end{array}$ & $p$ \\
\hline $\begin{array}{l}\text { Delirium during } \\
\text { admission }\end{array}$ & 30/106 (28) & 15/106 (14) & 0.028 \\
\hline $\begin{array}{l}\text { Discharged alive } \\
\text { within } 7 \text { days }\end{array}$ & 29/106 (27) & $81 / 106$ (76) & $<0.001$ \\
\hline $\begin{array}{l}\text { Decreased } \\
\text { dwelling* }\end{array}$ & $34 / 106(32)$ & 13/106 (12) & $<0.001$ \\
\hline $\begin{array}{l}\text { Functional decline } \\
\text { or death }\end{array}$ & 41/106 (39) & $15 / 105(14)$ & $<0.001$ \\
\hline \multicolumn{4}{|l|}{ Mortality } \\
\hline In-hospital & 12/106 (11) & 2/106 (2) & 0.013 \\
\hline 30 days & 14/106 (13) & $6 / 106(6)$ & NS \\
\hline 90 days & $24 / 106(23)$ & $8 / 105(8)$ & 0.004 \\
\hline 180 days & $35 / 103$ & 20/104 (19) & 0.011 \\
\hline \multicolumn{4}{|l|}{ Readmission } \\
\hline 30 days & 28/104 (27) & 19/106 (18) & NS \\
\hline 90 days & $48 / 105(46)$ & $37 / 105(35)$ & NS \\
\hline 180 days & 64/103 (62) & $53 / 105(50)$ & NS \\
\hline
\end{tabular}

*Patients admitted from home and discharged to a NH or LTCF, or deceased

to deteriorate or die during admission. Consistent with our findings, in a model to predict short-term mortality in patients hospitalized with CDI, delirium contributed the most points on the scale of weighted risk. ${ }^{5}$

The delayed effect on mortality by CDI following hospital discharge indicates that CDI may contribute to a decline in patient function and health over time, ultimately leading to death in many, an observation previously noted by others. ${ }^{2}$ Unique to our study is the association of dementia with functional decline and mortality, suggesting the interaction of cognitive impairment and CDI impacts later outcomes. These observations highlight the importance of CDI sequelae long after acute disease, especially in older people with cognitive impairment. Non-independent baseline status was previously shown to be a risk factor for long-term mortality in very old patients with CDI. ${ }^{6}$ In our study, high functional

Table 2 Analysis of Factors Associated with Late Mortality in CDI

\begin{tabular}{|c|c|c|c|c|c|c|}
\hline & \multicolumn{3}{|c|}{ Dementia } & \multicolumn{3}{|c|}{ Delirium } \\
\hline & Yes & No & $p$ & Yes & No & $p$ \\
\hline $\begin{array}{l}\text { Functional } \\
\text { decline or } \\
\text { death }\end{array}$ & $\begin{array}{l}14 / 21 \\
(67 \%)\end{array}$ & $\begin{array}{l}27 / 85 \\
(32 \%)\end{array}$ & 0.003 & $\begin{array}{l}17 / 30 \\
(57 \%)\end{array}$ & $\begin{array}{l}24 / 76 \\
(32 \%)\end{array}$ & 0.017 \\
\hline $\begin{array}{l}\text { 90-day } \\
\text { mortality }\end{array}$ & $\begin{array}{l}9 / 21 \\
(43 \%)\end{array}$ & $\begin{array}{l}15 / 85 \\
(18 \%)\end{array}$ & 0.013 & $\begin{array}{l}7 / 30 \\
(23 \%)\end{array}$ & $\begin{array}{l}17 / 76 \\
(22 \%)\end{array}$ & NS \\
\hline $\begin{array}{l}180 \text {-day } \\
\text { mortality }\end{array}$ & $\begin{array}{l}14 / 21 \\
(67 \%)\end{array}$ & $\begin{array}{l}21 / 85 \\
(25 \%)\end{array}$ & $<0.001$ & $\begin{array}{l}11 / 30 \\
(37 \%)\end{array}$ & $\begin{array}{l}24 / 76 \\
(32 \%)\end{array}$ & NS \\
\hline
\end{tabular}

dependence-observed over two times as frequently in cases - did not predict short- or long-term mortality.

The study was performed in two different settings and CCI varied between them related to population and care differences in Europe versus the USA; nonetheless, both in each site and combined, CCI did not predict disease severity nor mortality.

The interrelationships of cognitive and functional changes in older people affected by CDI with disease severity, mortality, and requirement for assisted living are complex and warrant larger, prospective studies.

Acknowledgements: The authors thank Dr. Jorge Sanchez Redondo for his help with data collection.

Corresponding Author: Maria-Jose Fernandez-Cotarelo, $M D, P h D$; Department of Internal Medicine, Hospital Universitario de Mostoles, Madrid, Spain (e-mail: mfcotarelo@salud.madrid.org).

Funding Information M.J.F.C. received a grant from the Instituto de Salud Carlos III (M-BAE 2015, Health Research and Development Strategy, Spain), the Spanish Foundation of Internal Medicine (FEMI), and the Madrid-Castilla la Mancha Society of Internal Medicine (SOMIMACA).

\section{Compliance with Ethical Standards:}

Conflict of Interest: The authors declare that they do not have a conflict of interest.

Disclaimer: This material is the result of work supported with resources and the use of facilities at the VAMC Salem Virginia. The contents do not represent the views of the U.S. Department of Veterans Affairs or the US Government.

\section{REFERENCES}

1. Abou Chakra CN, Pepin J, Sirad S, et al. Risk factors for recurrence, complications and mortality in Clostridium difficile infection: a systematic review. PLoS One 2014; 9:e98400. [PubMed: 24897375]

2. Dubberke ER, Butler AM, Reske KA, et al. Attributable outcomes of endemic Clostridium difficile- associated Disease in Nonsurgical Patients. Emerg Infect Dis 2008; 14:1031-1038. [PubMed: 18598621]

3. Kyne L, Merry C, O'Connell B, et al. Factors associated with prolonged symptoms and severe disease due to Clostridium difficile. Age Ageing 1999;28:109-113. [PubMed: 10350405]

4. Rao K, Micic D, Chenoweth E, et al. Poor functional status as a risk factor for severe Clostridium difficile infection in hospitalized older adults. J Am Geriatr Soc 2013;61:1738-1742. [PubMed: 24083842]

5. Archbald-Pannone L, McMurry T, Guerrant RL, et al. Delirium and other clinical factors with Clostridium difficile infection that predict mortality in hospitalized patients. Am J Infect Control 2015; 43: 690-693. [PubMed: 4490980]

6. Leibovici-Weissman Y, Atamna A, Schlesinger A, et al. Risk factors for short- and long-term mortality in very old patients with Clostridium difficile infection: A retrospective study. Geriatr Gerontol Int. 2016; https://doi. org/10.1111/ggi.12866. [PubMed: 27647625]

Publisher's Note: Springer Nature remains neutral with regard to jurisdictional claims in published maps and institutional affiliations. 